\title{
Las cárceles y población reclusa en Venezuela
}

\author{
A Posada ${ }^{1}$, M Díaz-Tremarias ${ }^{2}$ \\ ${ }^{1}$ Licenciado en Bioanálisis, Coordinadora de Programas y Proyectos de la Dirección Central de Extensión, \\ Universidad Central de Venezuela. \\ ${ }^{2}$ Magíster en Educación, Licenciado en Bioanálisis, Profesor Asociado, Jefe de la Cátedra de Toxicología, \\ Escuela de Bioanálisis, Universidad Central de Venezuela.
}

\section{RESUMEN}

A pesar de la importancia de los asuntos penitenciarios, en América Latina existen pocos estudios comprensivos y recomendaciones regionales con relación a este contexto. En este trabajo se describen las características de las cárceles y los reclusos en Venezuela, información recopilada a través de revisión documental y en visitas realizadas desde 1998-2006 a diferentes penales venezolanos, en el marco de las Jornadas de Salud insertas en el Programa Penitenciario de la Universidad Central de Venezuela, con el propósito de realizar un aporte que sirva como antecedente nacional y regional para la investigación en el ámbito penitenciario, que permita avanzar en el estudio de sus problemas y en la promoción e implementación de posibles soluciones.

Palabras clave: Prisión, Instalaciones para Atención de Salud, Recursos Humanos y Servicios, Salud Pública, Prisión.

\section{PRISONS AND INMATES POPULATION IN VENEZUELA}

\begin{abstract}
Despite the importance of prison issues in Latin America, there is little in the way of detailed local studies or recommendations on the subject. This article sets out to describe the situation concerning prisons and inmates in Venezuela. Data for this study was compiled from documentary sources and visits to a number of Venezuelan prisons from 1998 to 2006 as part of the Health Conference of the Programa Penitenciario de la Universidad Central de Venezuela, (Central University of Venezuela Prison Program). The program's aim was to make contributions towards research on the prison environment at national and regional levels that might serve as a precedent for further study of the problems and issues that exist, and promote and implement possible solutions.
\end{abstract}

Key words: Prison, Health Care Facilities, Manpower and Services, Public Health, Prison.

Texto recibido: enero 2008

Texto aceptado: febrero 2008

\section{INTRODUCCIÓN}

El sistema penitenciario en Venezuela confronta innumerables problemas, tales como el retardo procesal, el hacinamiento, el precario estado de los penales, la ausencia de una clasificación de presos, la carencia de servicios básicos indispensables y la presencia de armas y drogas, todo lo cual contribuye a la excesiva violencia que caracteriza a las instituciones penitenciarias en Venezuela. A esto se suma el escaso numero de funcionarios penitenciarios, con escasa o ninguna formación en el área ${ }^{1,2,3}$. Todas estas características, ponen en tela de juicio la función de "rehabilitación y reinserción social" que en teoría deberían lograr estas instituciones ${ }^{4}$, receptoras de la población delictiva del país y que resultan ser el reflejo agravado de los males que afectan a nuestra sociedad, encontrándose que la permanencia en estos centros de 
reclusión, lejos de rehabilitar, propicia vicios y mayores problemas a un sistema penitenciario ya desgastado y obsoleto.

En tal sentido, es necesaria su reforma para la exitosa ejecución de acciones educativas y terapéuticas a largo plazo. Tales acciones deben propiciarse teniendo como eje la salud del interno, en la convicción de que es un ser humano, miembro de una comunidad, que proviene de ella y vuelve a ella cuando recupera su libertad. Se considera que el éxito de estas estrategias contribuiría al bienestar de la sociedad en su conjunto, razón por la cual se presenta una descripción de este contexto, como un aporte que sirva como antecedente nacional y regional del contexto penitenciario a fin de avanzar en el estudio de sus problemas y en la promoción e implementación de posibles soluciones.

\section{LOS CENTROS PENITENCIARIOS EN VENEZUELA}

En Venezuela existen treinta cárceles nacionales, adscritas al Ministerio del Poder Popular para Relaciones Interiores y Justicia (MPPRIJ), ubicadas en diferentes regiones, sin embargo siete de ellas están situadas en el área metropolitana y en conjunto albergan, aproximadamente, una cuarta parte de toda la población penal del país 4 .

Del total de cárceles, solo una es un centro de reclusión exclusivamente femenino, los veintinueve centros restantes son para reclusos del género masculino aunque en quince de ellos se encuentran anexos femeninos con un bajo número de reclusas (generalmente entre 20-30).

Las leyes venezolanas ${ }^{5}$ distinguen entre los centros diseñados para internos penados o condenados y los destinados a detenidos preventivos o procesados, es decir aquellos que están a la espera del juicio. Se exige que los penados cumplan su condena en una penitenciaria, en una cárcel nacional, local o en una colonia penitenciaria en función del tipo pena que se les haya impuesto ${ }^{5,6}$. Otros centros, denominados internados judiciales o retenes, se destinan principalmente a procesados. Sin embargo, suele haber escasa relación entre la designación oficial de un centro y el tipo de internos que éste alberga, pues cualquiera que sea su denominación, en nuestras prisiones conviven tanto condenados como procesados, en proporciones aparentemente aleatorias; siendo este aspecto un rasgo crónico en nuestro país, incumpliendo así las normas internacionales que exigen la separación de procesados y penados. En la mayoría de estas cárceles conviven en un mismo espacio, individuos que han cometido delitos muy diferentes, sin atender a las diferencias de tratamiento que exige cada caso ${ }^{4}$.

En cuanto a la infraestructura de los centros penitenciarios, la población reclusa creció rápidamente durante los años 80 y 90 , pero no sucedió así con el espacio penitenciario disponible. Desde 1988 hasta 1996 no se construyeron nuevas prisiones y fue a finales de ese año que se abrieron nuevos centros, como anexos de otras prisiones ya existentes. Esta capacidad adicional, se vio desbordada por la pérdida de espacio, en enero de 1997, con el cierre y demolición de una de las principales prisiones del área metropolitana ${ }^{7}$.

El deterioro crónico de la infraestructura penitenciaria, la sobrepoblación y la carencia de presupuesto, atentan contra las condiciones mínimas para una vida adecuada. En la mayoría de estos centros se evidencian problemas en las tuberías de aguas blancas y negras, acumulación de basura y deterioro de los sanitarios y celdas, además de graves fallas en el suministro eléctrico y de agua potable ${ }^{8}$. El deplorable estado de las edificaciones penitenciarias obedece a su antigüedad (una media de 37 años), el uso intensivo y la falta de inversiones para su mantenimiento.

La capacidad de estas instituciones permite alojar a 15.000 prisioneros, sin embargo la población penal del país alcanzaba, para marzo de 2006, a 19.257 internos ${ }^{9}$, cifra que es variable, bien por deceso del interno, cumplimiento de la pena, traslados y los que han sido absueltos ${ }^{10}$.

Una consecuencia evidente de esta sobrepoblación es el hacinamiento. Mientras el número de plazas penitenciarias y recursos disponibles se mantiene constante para atender a un mayor número de reclusos, las condiciones de vida, dentro de las prisiones, tienden a desmejorar al facilitarse la insalubridad, el colapso de los servicios básicos y la violencia ${ }^{8}$.

Se registra un déficit del número de plazas para un índice de hacinamiento (porcentaje de la población que excede la capacidad instalada del sistema) equivalente al $14 \%{ }^{9}$. Sin embargo hay que observar con precaución este parámetro, pues si bien como dato general no supera el nivel considerado alarmante según criterios internacionales ${ }^{11}$ (20\% de hacinamiento), al analizar cada penal por separado, la situación puede resultar muy diferente. Por ejemplo, para diciembre 2006, en el Centro Penitenciario de Occidente (Santa Ana) se registraron 2.000 reclusos en un espacio diseñado para 600 personas 9 .

Respecto a la alimentación, se puede señalar que este es un aspecto que genera mayor número de abu- 
sos ya sea por distracción de fondos y/o apropiación indebida de los artículos relacionados, lo cual origina una precaria alimentación del recluso en cantidad y calidad, una deficiente preparación de los mismos y una distribución en condiciones indignas. Así, muchos internos dependen de sus familias y de la solidaridad entre ellos para su suministro y complemento $^{12}$.

Por otra parte se puede mencionar que la violencia carcelaria nacional tiene sus orígenes en dos grupos de factores causales. El primero de ellos, atribuidos a la propia institución: infraestructura precaria, hacinamiento, falta de clasificación de los reclusos, el trato dado a los visitantes, el retardo procesal, traslado a los tribunales, corrupción, excesos y abusos de custodios y guardias, impunidad, sostenimiento del ocio, entre otros. El segundo, originado por los propios actores: tráfico y consumo de drogas, conflictos por control territorial y el tráfico de armas ${ }^{13}$.

En la Tabla I se presentan las cifras de muertes violentas y heridos en las cárceles del país para el período comprendido entre los años 2003 al 2007.

En este sentido, expertos opinan que en Venezuela parece existir la pena de muerte en las penitenciarías; refieren que en Estados Unidos mueren más presos por pena de muerte que por rencillas, y tienen una población de 2.700 .000 presos; en Brasil, existen 400.000 presos y mueren 1,5 internos por cada mil; $y$ Venezuela, que tiene 20.000 presos, mueren 20 por cada mil'.

Al igual que la violencia, el consumo de drogas es una realidad en los penales venezolanos, hecho demostrado de manera indirecta a través de decomisos realizados por las autoridades competentes y de manera directa a través de la detección de metabolitos urinarios de drogas. Es así como en investigación realizada en cinco penales entre los años 2000 y 2003, con un total de 570 muestras, $280(49,1 \%)$ resultaron positivas para cocaína y marihuana. De estos sujetos, $29,3 \%$ niega en la entrevista todo consumo de drogas. Aunado a esto y dada la falta de diagnóstico clínico y psicológico se desconoce si se trata de consu- midores ocasionales o de verdaderos drogodependientes ${ }^{14}$.

Los sujetos que afirman consumir drogas estando recluidos, mencionan el consumo de marihuana, cocaína y sus derivados (crack y basuko), alcohol isopropílico ("agua loca"), condición que se repite en todos los penales estudiados y que lleva a pensar que el consumo de drogas por vía intravenosa es muy escaso en nuestras cárceles. Esto probablemente responda a razones culturales (temor a las agujas), a la dificultad para conseguir las inyectadoras y/o al mayor costo monetario de estas sustancias ${ }^{14,15}$.

\section{CARACTERÍSTICAS DE LOS RECLUSOS}

El número de personas recluidas en los diferentes establecimientos penales en el ámbito nacional, se mantuvo relativamente estable durante los últimos años, registrándose para el año 2006 una tasa de encarcelamiento de 71,24 por cien mil habitantes 9 .

Para marzo de 2006, de la población total de reclusos del país, $55,3 \%$ se encontraban en condición de procesados y $44,7 \%$ ya habían recibido condena. Si bien la proporción ha mejorado, con relación a años anteriores, persiste un número elevado de procesados dentro del sistema penitenciario venezolano, lo cual se debe en buena parte al retardo procesal. En la Tabla II se presentan las cifras totales de la población reclusa existente en nuestras cárceles entre los años 1999 al 2006 y discriminadas según su condición jurídica.

Es importante resaltar que la población recluida en los establecimientos penitenciarios es predominantemente masculina, en tanto que prevalecen los hombres con el 93,5\% (18.002) frente a un 6,5\% de mujeres $(1.255)^{9}$.

Los internos de los establecimientos penitenciarios venezolanos son hombres y mujeres jóvenes en su inmensa mayoría. Según datos del año 2005, entre la población masculina recluida predominan las personas entre 22 a 30 años $(45,6 \%)$, frente a las perso-

\begin{tabular}{lccccc}
\hline & $\begin{array}{c}2003 \\
\text { (ene-ago) }\end{array}$ & $\begin{array}{c}2004 \\
\text { (ene-ago) }\end{array}$ & $\begin{array}{c}2005 \\
\text { (ene-ago) }\end{array}$ & $\begin{array}{c}2006 \\
\text { (ene-dic) }\end{array}$ & $\begin{array}{c}2007 \\
\text { (ene-jul) }\end{array}$ \\
\hline Muertes violentas & 274 & 172 & 234 & 412 & 292 \\
\hline Heridos & 974 & 599 & 630 & 992 & 634 \\
\hline
\end{tabular}

Fuente: Datos 2003, 2004, 2005: MPPRIJ. Datos 2006: Observatorio Venezolano de Prisiones.

Tabla I. Violencia Carcelaria en Venezuela. 


\begin{tabular}{cccccc}
\hline Años/Población reclusa & Población reclusa & Procesados & $\mathbf{\%}$ & Penados & $\mathbf{\%}$ \\
\hline 1999 & 22.914 & 13.074 & 57 & 9.840 & 43 \\
\hline 2000 & 14.196 & 6.638 & 44,65 & 7.858 & 55,53 \\
\hline 2001 & 16.751 & 7.058 & 42,13 & 9.693 & 57,87 \\
\hline 2002 & 19.368 & 9.348 & 48,3 & 1.020 & 51,7 \\
\hline 2003 & 19.368 & 9.348 & 48,26 & 10.020 & 51,73 \\
\hline 2004 & 19.951 & 9.932 & 49,78 & 10.019 & 50,21 \\
\hline 2005 & 19.853 & 9.633 & 48,52 & 10.220 & 51,48 \\
\hline 2006 & 19.257 & 10.651 & 55,3 & 8.606 & 44,7 \\
\hline
\end{tabular}

Fuente: Programa Venezolano de Educación-Acción en Derechos Humanos (PROVEA) Informe anual 2005-2006.

Tabla II. Población Penitenciaria (Años 1999-2006).

nas mayores de 30 años $(38,4 \%)$ y jóvenes entre 18 y 21 años (14,5\%), con una edad promedio que oscila entre los 19 y 25 años. Pertenecen casi unánimemente a los estratos más humildes de la población, pues del total de personas recluidas, $61,3 \%$ tenían como lugar de residencia barrios o zonas marginales, donde ocupan viviendas precarias, con escasez de servicios básicos y de espacios personales?.

Igualmente, en su mayoría, proceden de familias con procesos de desvinculación, donde se aprecian carencias de afectividad, por lo general con ausencia de figura paterna y la autoridad familiar no ha sido ejercida satisfactoriamente provocando situaciones conflictivas. Son familias sin trabajo y con pocas aspiraciones, que luchan por la supervivencia diaria ${ }^{4}$.

En relación a la ocupación profesional, la mayoría está constituida por obreros de diferentes disciplinas: construcción, plástico, manufacturero, conductores de medios de transporte y personas de ocupaciones afines; artesanos, operadores y electricistas. Al observar las condiciones laborales que presentaban a su ingreso en prisión, la inmensa mayoría no tenía empleo fijo o realizaban trabajos eventuales o relacionados con la economía informal ${ }^{16}$.

Si bien en algunos establecimientos penitenciarios se han hecho esfuerzos para proporcionar capacitación laboral a los internos, no se puede considerar una política sostenida y extendida hacia todos los centros penitenciarios?.

Para el segundo semestre de 2005 se determinó que un $21,8 \%$ de la población penal, se encontraba incorporada a programas educativos ("misiones") del actual gobierno $(15 \%)$ y a otras formas de enseñanza $(6,3 \%)$. Para este mismo período, se registra que aproximadamente un $30 \%$ tiene estudios de primaria, $50 \%$ estudios de secundaria y solo $3 \%$ nivel superior, lo cual significa que un $83 \%$ de la población reclusa, para esa fecha, estaba escolarizada frente a un $8 \%$ de analfabetismo?.

En cuanto a las diferentes nacionalidades presentes, la población reclusa es mayoritariamente venezolana ${ }^{17}$.

En relación al género y estado civil, del total de la población masculina, $70 \%$ son solteros, $12,4 \%$ casados y $8,6 \%$ unidos. La mayoría de la población reclusa femenina son mujeres con edades que oscilan entre 20 a 30 años y que poseen las siguientes características: $45 \%$ solteras, $90 \%$ con hijos, más del $50 \%$ son procesadas y $17 \%$ extranjeras. El $64 \%$ se encuentra recluido por delitos relacionados con drogas?.

Generalmente presentan menores problemas de hacinamiento y mejores condiciones de reclusión que los hombres; sin embargo, dado su bajo número, en algunos estados del país se encuentran recluidas en establecimientos inapropiados. Presentan serios problemas en cuanto a su libertad sexual, el beneficio de visitas conyugales para las internas fue reconocido por la legislación venezolana en 1992, pero sólo a partir de 1999 se incorporó como línea de trabajo la dotación de la infraestructura para garantizarlo ${ }^{8}$. Aunque actualmente las reciben, son limitadas; situación que se convierte en una diferencia en el trato de las mujeres y que contrasta llamativamente con la de los hombres ${ }^{4}$. Hasta finales del año 2006, no se habían evidenciado acciones tendentes a mejorar esta situación, a pesar de la evidente necesidad de incorporar en las políticas penitenciarias una perspectiva de género 9 . 
Las condiciones generales de vida al interior de nuestras prisiones, repercuten en una mayor incidencia de enfermedades propias de ambientes hacinados e insalubres. En investigaciones realizadas en 8.232 internos, entre los años 2001 a 2003 se mencionan como principales causas de consulta las siguientes patologías: enfermedades de la piel $(53 \%)$ tales como micosis, dermatitis, y escabiosis, entre otras; gastroenterológicas (12\%); quirúrgicas $(10 \%)$; enfermedades respiratorias $(9 \%)$ e infecciones de transmisión sexual $(8 \%)$, cuadros que en general, suelen ser mas frecuentes entre los reclusos que en el resto de la población ${ }^{8,10}$. Las infecciones de transmisión sexual y sus factores de riesgo, merecen mención aparte, razón por la cual serán presentadas más ampliamente en entregas posteriores. En la situación de salud de las mujeres se registra la existencia de enfermedades crónicas relacionadas con hipertensión, problemas respiratorios y problemas renales, entre otros ${ }^{9,18}$.

Aunado a esto, en el interior de los penales se establece una marginalidad dentro de la marginalidad, según el nivel de recursos y medios, que poseen estas personas, por esta razón es posible entender que se agrupen entre sí, en base a cierto patrón común. Estas formas de pertenencia generan mecanismos de autosostenimiento que refuerzan actitudes y comportamientos ${ }^{19}$ y en muchas ocasiones, contribuyen a la violencia.

Existen reglamentos, criterios y normas que rigen la conducta de los reclusos y del personal que allí labora y que forman parte de la cultura dominante, paralelamente se mantienen acuerdos sociales implícitos basados en intereses compartidos, en un compromiso grupal que cohesiona, pasando a ser una estrategia adaptativa al medio carcelario que conforman la subcultura carcelaria, la cual posee sus propias reglas y se expresa como conciencia grupal, al reproducir elementos culturales de identidad colectiva pues se establecen códigos propios de honor, de apoyo, de castigo, de censura, de defensa de la territorialidad, entre otros. Ambos tipos de reglas coexisten y regulan la interacción de los reclusos ${ }^{19}$.

\section{HACIA DÓNDE VAMOS}

Hasta ahora, se ha demostrado una total incompetencia para abordar y resolver la situación penitenciaria en nuestro país. Sin embargo, el actual gobierno reconoce los problemas de este contexto y ha comenzado a implementar el proyecto denominado "Humanización Penitenciaria", caracterizado por un sistema que apunte a la rehabilitación del interno; con procedimientos que aseguren sus derechos humanos; con atención integral al recluso: salud, trabajo, deporte y recreación; dirigido por penitenciaristas profesionales; bajo administración descentralizada; con preferencia al régimen abierto y colonias agropecuarias; que incluya la atención postpenitenciaria (reinserción) y previendo la creación de un ente penitenciario autónomo ${ }^{20}$.

Sin dejar de reconocer el mérito para el inicio de estas acciones, sigue evidenciándose cierta debilidad en la voluntad política, la ausencia de un diagnóstico individualizado, sistemático y permanente de esta población, no solo desde el punto de vista médico, sino desde el punto de vista de sus habilidades y destrezas, por lo tanto, podría manifestarse cierto escepticismo acerca de la ejecución y estabilidad en el tiempo de estas acciones, dado que en nuestro país se han diseñado nuevas políticas y estrategias, se han suscrito nuevos acuerdos, pero escasean los recursos materiales y humanos necesarios para su aplicación, pues se pierden en el entramado burocrático, el cambio de autoridades y la corrupción.

\section{REFERENCIAS BIBLIOGRÁFICAS}

1. Linares M. Sistema Penitenciario Venezolano. Caracas, Venezuela: Centro Gumilla; 1997.

2. Centro Gumilla. SIC, Caracas; Mayo 1998; Año LXI. No. 604: 25-30.

3. Vivanco JM. Castigados antes del juicio: Condiciones de las prisiones en Venezuela. New York: Human Rights Watch; 1998.

4. Posada A. Historia General de las Instituciones Penitenciarias. En/In Posada A, Salazar E. Las Cárceles... una visión. Caracas. Ediciones del Rectorado de la Universidad Central de Venezuela. 2004: 13-36.

5. Ley de Régimen Penitenciario. Gaceta Oficial No. 36975, 19 de junio de 2000.

6. Código Orgánico Procesal Penal. Gaceta Oficial No. 38536, 4 de noviembre 2006.

7. López E. Llegó la hora de pensar en las víctimas de la delincuencia. El Nacional, 2001, agosto 25, Cuerpo D: 4.

8. Programa Venezolano de Educación-Acción en Derechos Humanos. Informe Anual 2003-2004. Derechos de las personas detenidas y encarceladas. Caracas, Autor. [Fecha de acceso 15 de julio de 2005] Disponible en http://www.derechos.org.ve

9. Programa Venezolano de Educación-Acción en Derechos Humanos. Informe Anual 2006-2007. 
Derechos de las personas detenidas y encarceladas. Caracas, Autor. [Fecha de acceso 10 de noviembre de 2007] Disponible en http://www.derechos. org.ve.

10. Salazar E. Programa de Extensión Penitenciario. En/In Posada A, Salazar E. Las cárceles... Una visión. Caracas. Ediciones del Rectorado, Universidad Central de Venezuela. 2004: 51-70.

11. Carranzas E. Justicia penal y sobrepoblación carcelaria. México. Editorial Siglo XXI. 2001: 51.

12. Torres A. Realidad de los servicios de alimentación en los centros penitenciarios. En/In Posada A, Salazar E. Las cárceles... Una visión. Caracas. Ediciones del Rectorado, Universidad Central de Venezuela. 2004: 75-83.

13. Padrón M.A. Violencia Carcelaria. En/In Posada A, Salazar E. Las cárceles... Una visión. Caracas. Ediciones del Rectorado, Universidad Central de Venezuela. 2004: 125-139.

14. Díaz Tremarias M, Posada A. Detección de drogas de abuso en centros penitenciarios venezolanos. Revista de la Facultad de Medicina de la Universidad Central de Venezuela, 2003; 26 (2): 105111.

15. Díaz Tremarias M. Una aproximación al consumo de drogas en centros penitenciarios venezolanos. En/In Posada A, Salazar E. Las cárceles... Una vi- sión. Caracas. Ediciones del Rectorado, Universidad Central de Venezuela. 2004: 115-121.

16. Wyssenbach P. El Problema Penitenciario. SIC 1998 (605): 235-245.

17. Ministerio de Interior y Justicia. Dirección General de Custodia y Rehabilitación del Recluso. Dirección de Fiscalización e Investigación. Departamento de Estadísticas, Venezuela, 2001.

18. Instituto Nacional de la Mujer. Informe sobre la situación de las mujeres privadas de libertad. Caracas, 2005: 18.

19. Díaz Tremarias M. Determinantes y resultantes del consumo de drogas en centros penitenciarios venezolanos. Revista Eradicciones, Chile. 2007: En prensa.

20. Ministerio del Poder Popular para Relaciones Interiores y Justicia. Proyecto de Humanización Penitenciaria. [Consultado el 12 de diciembre de 2007] Disponible en http://www.mpprij.gob.ve.

\section{CORRESPONDENCIA}

Universidad Central de Venezuela.

Facultad de Medicina.

Escuela de Bioanálisis, Piso 3.

Cátedra de Toxicología.

Caracas 1051, Venezuela. 